\title{
The influence of di-(2-ethylhexyl) phthalate on steroidogenesis by the ovarian granulosa cells of immature female rats
}

\author{
I Svechnikova, K Svechnikov and O Söder \\ Pediatric Endocrinology Unit, Department of Woman and Child Health, Karolinska Institute and University Hospital, Q2:08, 171 76 Stockholm, Sweden \\ (Correspondence should be addressed to I Svechnikova; Email: irina.svechnikova@ki.se)
}

\begin{abstract}
Phthalate esters are known to exert harmful effects on mammalian reproduction and fertility, but their potential adverse effects on the hormonal functions of the ovary have not yet been elucidated in detail. Here, we investigated the effects of di-(2-ethylhexyl) phthalate (DEHP) on the hypothalamic-pituitary-gonadal axis of young developing female rats, as well as on ex vivo steroidogenesis by granulosa cells (GCs) and secretion of LH by gonadotropes. Exposure of 20-day-old female rats to $500 \mathrm{mg}$ DEHP by oral gavage once daily for 10 days reduced their serum levels of progesterone and estradiol, while tending to enhance levels of LH. Furthermore, primary cultures of GCs isolated from these rats exhibited an attenuated capacity to produce progesterone in response to stimulation by
\end{abstract}

LH and FSH, as well as a lower degree of transport of endogenous cholesterol into mitochondria. Moreover, the ability of primary cultures of pituitary cells isolated from DEHPtreated rats to produce and secrete $\mathrm{LH}$ in response to GnRH was significantly enhanced. In addition, 2-ethylhexanoic acid, a metabolite of DEHP, significantly potentiated GnRH-stimulated production of LH by cultures of pituitary cells isolated from untreated 20-day-old female rats. Together, these data indicate that DEHP exerts dual effects on the pituitary-gonadal axis, stimulating the hormonal function of the pituitary and, at the same time, by inhibiting steroidogenesis by GCs.

Journal of Endocrinology (2007) 194, 603-609

\section{Introduction}

Phthalates, including the widely used plasticizer di(2-ethylhexyl) phthalate (DEHP), are the most abundant pollutants of our general environment. These substances are components of food wraps and many medical devices (e.g. tubing, blood bags, and dialysis equipment), as well as of many cosmetic products. With time, they are leached out of these plastic products, and their volatility results in pronounced human exposure to phthalates.

Investigations on the influence of phthalates on the female reproductive system have focused primarily on fertility and teratogenicity in experimental animals and cattle (Collins et al. 1992). Little information concerning the effects of phthalates on pregnant women is presently available, although chronic occupational exposure of female factory workers to high levels of phthalates has been reported to be associated with reduced rates of pregnancy and an elevated frequency of miscarriage (Aldyreva et al. 1975). Exposure of adult rats to DEHP results in hypoestrogenic anovulatory cycles and polycystic ovaries (Davis et al. 1994a).

In the intestine and liver of humans and animals, DEHP is rapidly hydrolyzed by esterases to yield mono-(2-ethylhexyl) phthalate (MEHP) and 2-ethylhexanol (Rowland 1974,

Albro et al. 1983); and this hexanol is subsequently oxidized enzymatically to 2-ethylhexanoic acid (2-EHXA; Collins et al. 1992). MEHP, 2-ethylhexanol, and/or their metabolites are the immediate inducers of the majority of enzymes known to be affected by exposure to DEHP (Pollack et al. 1989).

In primary cultures of rat granulosa cells (GCs), stimulation of adenylate cyclase and progesterone synthesis by folliclesimulating hormone (FSH) is inhibited by MEHP (Treinen et al. 1990). Moreover, this compound suppresses estradiol production by the same cells by a mechanism that is independent of the elevation in cAMP levels caused by FSH (Davis et al. 1994b). This latter phenomenon reflects direct inhibition by MEHP of transcription of the gene that encodes aromatase, the enzyme that converts androgen to estrogen (Lovekamp \& Davis 2001). DEHP also suppresses the production of estradiol and ovulation in cycling rats (Davis et al. 1994a). However, in the case of immature female rats, the influence of in vivo administration of DEHP on the hypothalamic-pituitary-gonadal (HPG) axis and progesterone production by GCs isolated and cultured ex vivo has not yet been characterized. Here, we investigated the effects of DEHP on the HPG axis of immature female rats, as well as ex vivo steroidogenesis by GCs and secretion of luteinizing hormone (LH) by gonadotropes. 


\section{Materials and Methods}

\section{Materials}

Dulbecco's modified Eagle's medium (DMEM)-Ham's nutrient mixture F-12 (supplemented with L-glutamine and HEPES), BSA ( $7 \cdot 5 \%$ solution), cholesterol lipids $(250 \times)$, and penicillin-streptomycin (Gibco/BRL, Life Technologies); ovine FSH, ovine LH, 22R-hydroxycholesterol (22ROHC), DEHP, EHXA, and aminoglutethimide (AMG; an inhibitor of cytochrome P450scc; Sigma); MEHP (TCI Europe, Brussels, Belgium); trilostane (an inhibitor of $3 \beta-$ hydroxysteroid dehydrogenase; Stegram Pharmaceuticals, Billinghurst, Sussex, UK); and the cell proliferation WST-1 kit (Roche Diagnostic Gmbh) were purchased from the sources indicated. The rat LH used for iodination (NIDDKrLH-I-10, Lot \# AFP-11536B), antiserum against rat LH (NIDDK-anti-rLH-S11, Lot \# AFPC697071P), and LH utilized as a reference standard (NIDDK-rLH-RP-3, Lot \# AFP-7187B) were obtained from Dr Parlow of the National Hormone and Peptide Program, NIDDK, USA. The secondary goat antiserum against rabbit IgG was purchased from the Sigma.

\section{Animals}

Immature (20-day-old) Sprague-Dawley female rats (B\&K Laboratories, Sollentuna, Sweden) were randomly divided into two groups of ten animals each, one of which was administered DEHP $(500 \mathrm{mg} / \mathrm{kg}$ dissolved in corn oil) and the other a corresponding volume of corn oil alone (controls) by gavage once daily for 10 days. This dose of DEHP has been shown to effectively elicit response, but not toxicity in male rats of approximately the same age (Supornsilchai et al. 2007). Twenty-four hours after the last gavage, the animals were anesthetized with pentobarbital, blood samples collected by intracardiac puncture, and plasma prepared by centrifugation at $2500 \mathrm{~g}$ for $15 \mathrm{~min}$, and thereafter maintained at $-80^{\circ} \mathrm{C}$ for subsequent analysis of progesterone, estradiol, and LH. The ovaries and pituitary glands were removed from the same rats for isolation of granulosa and pituitary cells.

The animal experiments performed here were preapproved by the Northern Stockholm Committee for Ethical Animal Experimentation.

\section{Isolation and primary culture of GCs}

GCs were isolated from immature rat ovaries, as described previously (Treinen et al. 1990). In brief, after trimming away the surrounding tissue, the ovaries were placed in $3 \mathrm{ml}$ DMEM:F-12 (1:1) medium supplemented with penicillin $(100 \mathrm{U} / \mathrm{ml})$, streptomycin $(100 \mu \mathrm{g} / \mathrm{ml})$, and $0.5 \% \mathrm{BSA}$ and then punctured with a 25 -gauge needle. The resulting cell suspension was first filtered through a $70 \mu \mathrm{m}$ cell strainer, following which the cells were collected by centrifugation at $200 \mathrm{~g}$ for $7 \mathrm{~min}$, washed once with the same medium, and thereafter resuspended in a corresponding volume of fresh DMEM:F-12 (1:1) medium containing cholesterol lipid concentrate (1:250; added to mimic the cholesterol content of the follicular fluid in vivo). Subsequently, 100000 GCs in $100 \mu \mathrm{l}$ were placed into each well of 96-well plates (Falcon, Franklin Lakes, NJ, USA), cultured for $2 \mathrm{~h}$ at $37^{\circ} \mathrm{C}$ under $5 \%$ $\mathrm{CO}_{2}$ and then incubated in the absence or presence of FSH $(50 \mathrm{mU} / \mathrm{ml}), \mathrm{LH}(100 \mathrm{mU} / \mathrm{ml})$, and/or 22R-OHC $(10 \mu \mathrm{M})$ for an additional $24 \mathrm{~h}$ in a total volume of $250 \mu \mathrm{l}$.

\section{Isolation and primary culture of pituitary cells}

Cells were isolated from the anterior pituitary glands of both control and DEHP-treated rats as follows: the glands were first minced utilizing a scalpel, and the pieces thus obtained were incubated with collagenase $(2 \mathrm{mg} / \mathrm{ml})$ for $30 \mathrm{~min}$ at $37^{\circ} \mathrm{C}$. The resulting cell suspension was then filtered through nylon gauze $(70 \mu \mathrm{m}$; Becton, Franklin Lakes, NJ, USA), following which the cells were collected by centrifugation at $300 \boldsymbol{g}$ for $7 \mathrm{~min}$, washed twice with DMEM:F-12 (1:1) medium containing $0.5 \%(\mathrm{w} / \mathrm{v}) \mathrm{BSA}$, and finally resuspended in the same medium supplemented with $15 \mathrm{mM}$ HEPES ( $\mathrm{pH} 7 \cdot 4$ ), $0 \cdot 5 \% \mathrm{BSA}$, glutamine $(365 \mathrm{mg} / \mathrm{l})$, penicillin $(100 \mathrm{IU} / \mathrm{ml})$, and streptomycin $(100 \mu \mathrm{g} / \mathrm{ml})$. The viability of these cells, as assessed by Trypan blue exclusion, was routinely $>90 \%$.

Ten thousand of these cells were placed into each well of 96-well plates. They were pre-incubated for $1 \mathrm{~h}$ at $37^{\circ} \mathrm{C}$ under $5 \% \mathrm{CO}_{2}$ and subsequently cultured in the absence or presence of gonadotropin-releasing hormone $(\mathrm{GnRH} ; 0 \cdot 01$, $0 \cdot 1$, and $1 \cdot 0 \mathrm{ng} / \mathrm{ml}$ ) for an additional $3 \mathrm{~h}$. In similar experiments, cells isolated from 20-day-old female rats, treated neither with DEHP nor with vehicle, were cultured with or without DEHP, MEHP, or EHXA $(1 \mu \mathrm{M})$ for $24 \mathrm{~h}$ at $37^{\circ} \mathrm{C}$, at which time fresh culture medium containing the same compound together with GnRH $(1 \mathrm{ng} / \mathrm{ml})$ was added and incubation continued for another $3 \mathrm{~h}$. Following these procedures, the culture media were collected and stored at $-80^{\circ} \mathrm{C}$ until subsequent assay for $\mathrm{LH}$.

\section{Determination of hormone concentrations}

Plasma samples and media from the GC cultures were used for determination of the concentrations of progesterone and estradiol present employing the Coat-a-Count RIA and Double Antibody Estradiol kits respectively (Diagnostic Products Corp., Los Angeles, CA, USA) in accordance with the manufacturer's instructions. In addition, the LH levels in the same samples of serum media from the pituitary cell cultures were measured employing rat LH labeled with ${ }^{125}$ I by the routine Chloramine- $\mathrm{T}$ procedure.

\section{Monitoring cholesterol transport into mitochondria}

For this purpose, $100000 \mathrm{GCs}$ isolated from control or DEHP-treated rats and suspended in $100 \mu \mathrm{l}$ medium were placed into each well of 96-well Falcon plates (Falcon), where 
they were first incubated at $37^{\circ} \mathrm{C}$ under an atmosphere containing $5 \% \mathrm{CO}_{2}$ for $24 \mathrm{~h}$. Thereafter, fresh medium containing AMG $(0.5 \mathrm{mM})$, an inhibitor of cytochrome P450scc, and trilostane $(5 \mu \mathrm{M})$, an inhibitor of $3 \beta$-hydroxysteroid dehydrogenase, was added and incubation continued for an additional $30 \mathrm{~min}$, following which the medium was supplemented with $\mathrm{LH}(100 \mathrm{mU} / \mathrm{ml})$ and incubation performed for $3 \mathrm{~h}$ more. Inhibition of mitochondrial cholesterol metabolism by AMG and trilostane results in accumulation of this steroid in this organelle in response to hormonal stimulation (Potts et al. 1978, Brueggemeier et al. 2005).

Subsequently, the cells were washed twice with the basic medium and then cultured in the presence of trilostane $(5 \mu \mathrm{M})$ in $\mathrm{AMG}$-free medium at $37^{\circ} \mathrm{C}$ under $5 \% \mathrm{CO}_{2}$ for $2 \mathrm{~h}$, after which the levels of pregnenolone and its metabolite dehydroepiandrosterone (DHEA; formed by cytochrome $\mathrm{P} 450 \mathrm{c} 17$ via the $\Delta^{5}$ pathway) in the medium were measured. The total combined amount of these steroids produced by the cells reflects the amount of cholesterol available to the cytochrome P450scc system (Potts et al. 1978). After lysing the cells with the M-PER Mammalian Protein Extraction Reagent (Pierce, Rockford, IL, USA), protein was determined using the Micro BCA Protein Assay from the same company and the total amount of these hormones produced expressed per milligram protein.

\section{Statistical analysis}

Differences in the values obtained for animals or cells subjected to different treatments were evaluated for statistical significance with Student's $t$-test and one-way ANOVA, followed by the Student-Newman-Keul's or Dunn's test, in all cases employing the SigmaStat (v 3.00) software package (SPSS Inc., Chicago, IL, USA).

\section{Results}

Oral administration of DEHP to immature female rats decreases their serum levels of progesterone and estradiol

Administration of DEHP by oral gavage to 20-day-old female rats for 10 days resulted in two- and fivefold reductions in the concentrations of progesterone and estradiol respectively in their plasma, together with a tendency toward an elevated level of plasma LH (Fig. 1A-C). This exposure did not exert any obvious toxic effects on the animals, as reflected in their unaltered body and ovary weights (Table 1).

Treatment of immature female rats with DEHP inhibits ex vivo steroidogenesis by their GCs

In an attempt to identify the primary target through which DEHP impairs the biosynthesis of sex hormones, the capacities of GCs isolated from treated and control rats to produce progesterone under ex vivo conditions were
A

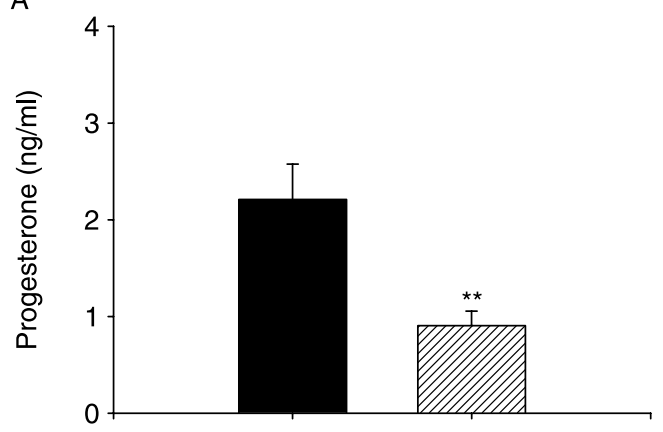

B

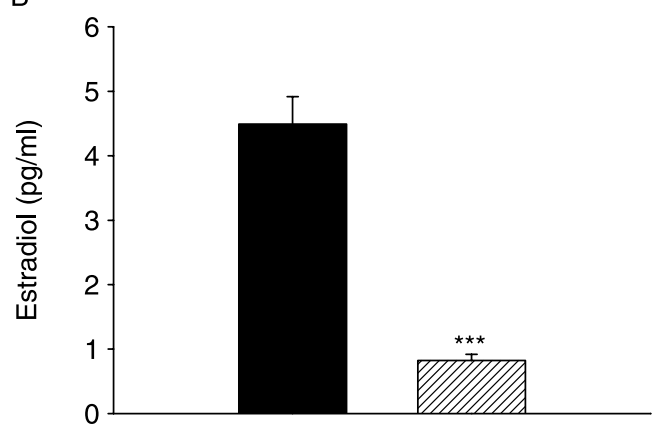

C

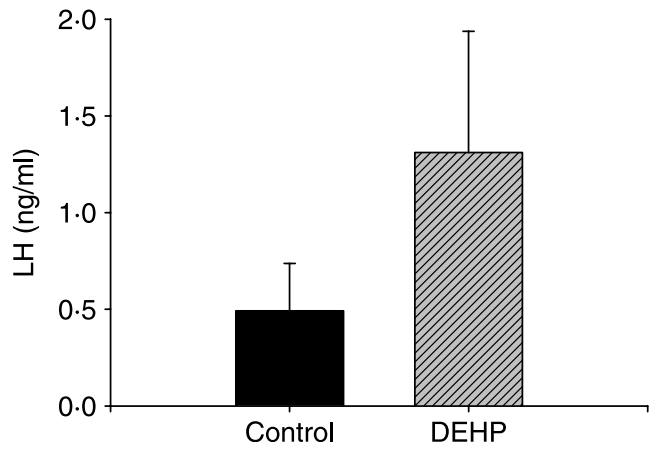

Figure 1 Plasma levels of progesterone (A), estradiol (B), and $\mathrm{LH}(\mathrm{C})$ in 20-day-old female rats exposed to DEHP ( $500 \mathrm{mg} / \mathrm{kg}$ per day) by oral gavage for 10 days. The control animals received a corresponding volume of vehicle (corn oil) alone by the same route. Each bar represents the mean \pm S.E.M. $(n=9-10)$. ${ }^{* *} P<0 \cdot 01$;

$* * * P<0 \cdot 001$ when compared with the corresponding control value.

compared. Following stimulation with FSH or LH, progesterone production by GC isolated from DEHP-treated animals was $30 \%$ lower $(P<0 \cdot 05)$ than by control cells (Fig. 2). Moreover, these cells isolated from young developing female rats, whether treated or not, were poorly responsive to gonadotropins, suggesting that the signaling machinery involved was not yet fully developed. More detailed information concerning the site in steroidogenesis inhibited by DEHP was provided using 22R-OHC, a derivative of cholesterol that diffuses readily across membranes. DEHP exerted no effect on progesterone synthesis from $22 \mathrm{R}-\mathrm{OHC}$, 
Table 1 The weights of the whole body and both ovaries of 20-day-old female rats prior to and following treatment with di-(2-ethylhexyl) phthalate (DEHP) or vehicle alone for 10 days

\begin{tabular}{|c|c|c|c|}
\hline & $\begin{array}{l}\text { Age } \\
\text { (days) }\end{array}$ & $\begin{array}{l}\text { Body weight } \\
\text { (g) }\end{array}$ & $\begin{array}{l}\text { Weight of ovaries } \\
(\mathrm{mg})\end{array}$ \\
\hline \multicolumn{4}{|l|}{ Group } \\
\hline Prior to treatment & 20 & & \\
\hline Control & & $42 \cdot 6 \pm 0 \cdot 9$ & ND \\
\hline DEHP & & $45 \cdot 7 \pm 1 \cdot 6$ & ND \\
\hline Following treatment & 30 & & \\
\hline Control & & $69 \cdot 5 \pm 1 \cdot 7$ & $12 \cdot 3 \pm 0 \cdot 6$ \\
\hline DEHP & & $77 \cdot 0 \pm 3 \cdot 7$ & $12 \cdot 7 \pm 0 \cdot 7$ \\
\hline
\end{tabular}

The rats received DEHP $(500 \mathrm{mg} / \mathrm{kg}$ ) or the corresponding volume of vehicle (corn oil) alone each day for 10 days $(n=10)$. ND, not determined.

suggesting that this phthalate may be disturbing the translocation of cholesterol across mitochondrial membranes.

Treatment of immature female rats with DEHP reduces ex vivo transport of cholesterol into the mitochondria of their GCs

Since the suppression by DEHP of steroidogenesis in GCs was abolished by 22R-OHC, we examined whether treatment with this phthalate affects the transport of cholesterol into the mitochondria of GCs. Indeed, the level of DHEA produced (which reflects the amount of cholesterol available to the mitochondrial cytochrome P450scc system) was significantly reduced $(33 \%)$ by such treatment (Fig. 3). The level of pregnenolone detected was negligible, indicating that when $3 \beta$-HSD (3 $\beta$-hydroxysteroid dehydrogenase) was blocked, this entire compound was converted further into DHEA by CYP17 $\alpha$.

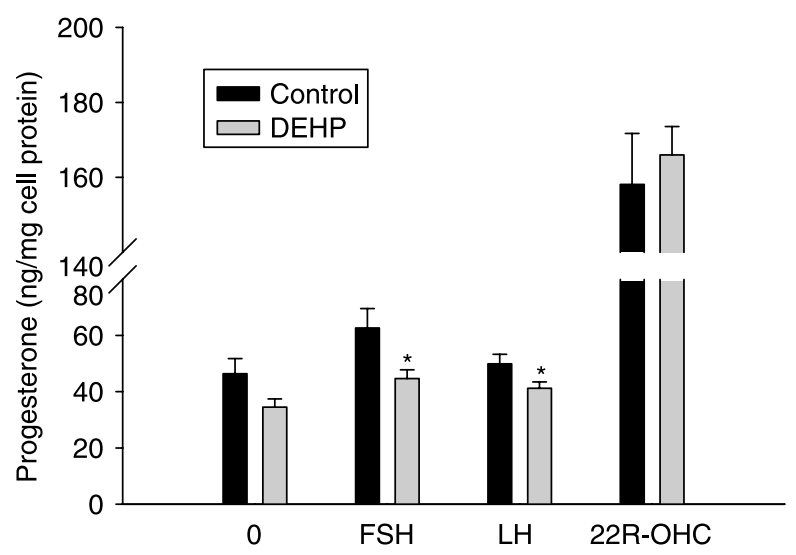

Figure 2 Progesterone production by granulosa cells isolated from the ovaries of DEHP-treated (gray bars) and control (black bars) 20-dayold female rats and cultured ex vivo. Following incubation of these cells with FSH, LH, and 22R-OHC or vehicle only (0) for $24 \mathrm{~h}$, the concentrations of progesterone in the culture media were determined by RIA. These results depict the means \pm S.E.M. of the values obtained with three independent preparations of granulosa cells. ${ }^{*} P<0 \cdot 05$ when compared with the corresponding control value.

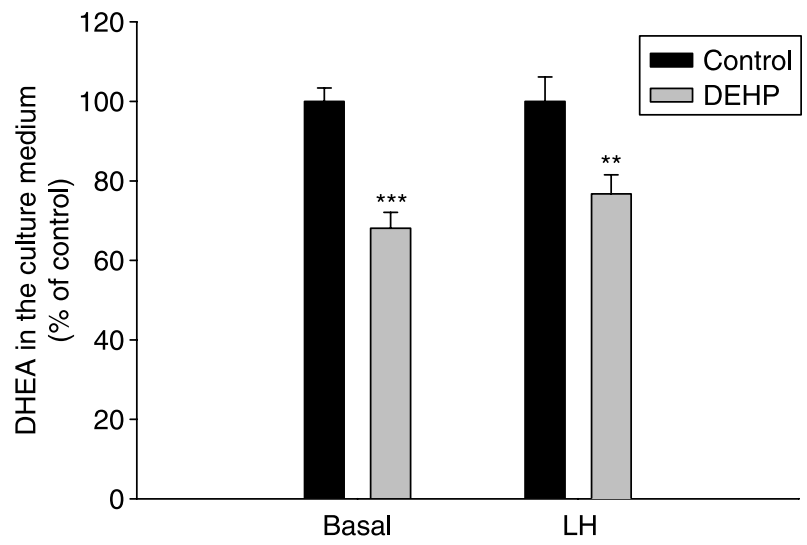

Figure 3 Ex vivo transport of cholesterol into the mitochondria of granulosa cells isolated from DEHP-treated (gray bars) and control (black bars) immature female rats. Following pretreatment of the cells with aminoglutethimide (AMG; $0.5 \mathrm{mM}$ ) and trilostane $(5 \mu \mathrm{M})$ for $30 \mathrm{~min}$ and subsequent incubation in the presence $(\mathrm{LH})$ or absence (basal) of $\mathrm{LH}(100 \mathrm{mU} / \mathrm{ml})$ for $3 \mathrm{~h}$, the DHEA present in the culture medium was measured by RIA procedure. The results presented are the means \pm S.E.M. for three independent experiments. ${ }^{* *} P<0 \cdot 01$; ${ }^{* * *} P<0 \cdot 001$ when compared with the corresponding control values.

Treatment of immature female rats with DEHP enhances ex vivo secretion of $\mathrm{LH}$ by their pituitary cells

Our findings that the serum levels of steroid hormones in DEHP-treated immature female rats were reduced, together with a tendency toward an increase in the serum level of LH, suggest that the ex vivo observations presented above might reflect activation of the pituitary by the attenuated levels of steroid hormones in the treated animals. Consequently, release of LH by pituitary cells isolated from control and DEHP-treated rats was examined and proved to be significantly (twofold) elevated, both with and without stimulation by GnRH, following exposure (Fig. 4).

Effects of in vitro exposure to DEHP or its metabolites on $\mathrm{LH}$ secretion by pituitary cells isolated from immature female rats treated neither with DEHP nor with vehicle

Subsequent experiments were designed to test the hypothesis that DEHP and/or metabolites of this phthalate can directly stimulate the pituitary of developing rats to produce LH. In order to assess contribution of all these compounds into the activating effect of DEHP on these cells observed ex vivo, the effects of DEHP and its predominant metabolites, MEHP and 2-EHXA, on hormonal function of cultured pituitary cells were studied. Indeed, 2-EHXA, but neither DEHP nor MEHP, significantly enhanced (by 30\%, P<0.05) GnRHstimulated production of LH by cultures of pituitary cells isolated from 20-day-old female rats with no pretreatment whatsoever (Fig. 5). However, this compound had no effect on basal production of LH by the same cells (the control and 2 -EHXA-exposed values were $40 \cdot 8 \pm 1 \cdot 0$ and $46 \cdot 7 \pm 2 \cdot 5 \mathrm{ng}$ / $10^{4}$ cells $/ 24 \mathrm{~h}$ respectively). 


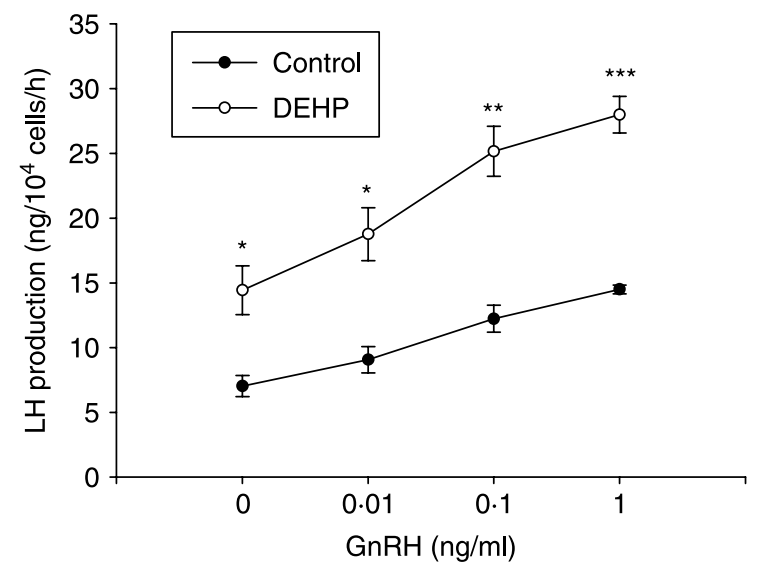

Figure 4 Ex vivo production of $\mathrm{LH}$ by pituitary cells isolated from DEHP-treated (open circles) and control (filled circles) immature female rats, both with and without stimulation by $\mathrm{GnRH}$. The pituitary cells were incubated without or with various concentrations of $\mathrm{GnRH}$ for $3 \mathrm{~h}$, after which the concentration of $\mathrm{LH}$ in the culture medium was determined employing RIA procedure. The results represent means \pm s.E.M. of three independent pituitary cell preparations. ${ }^{*} P<0 \cdot 05 ;{ }^{* *} P<0 \cdot 01 ;{ }^{* * *} P<0 \cdot 001$ when compared with the control value (i.e. cells from control animals without exposure to DEHP).

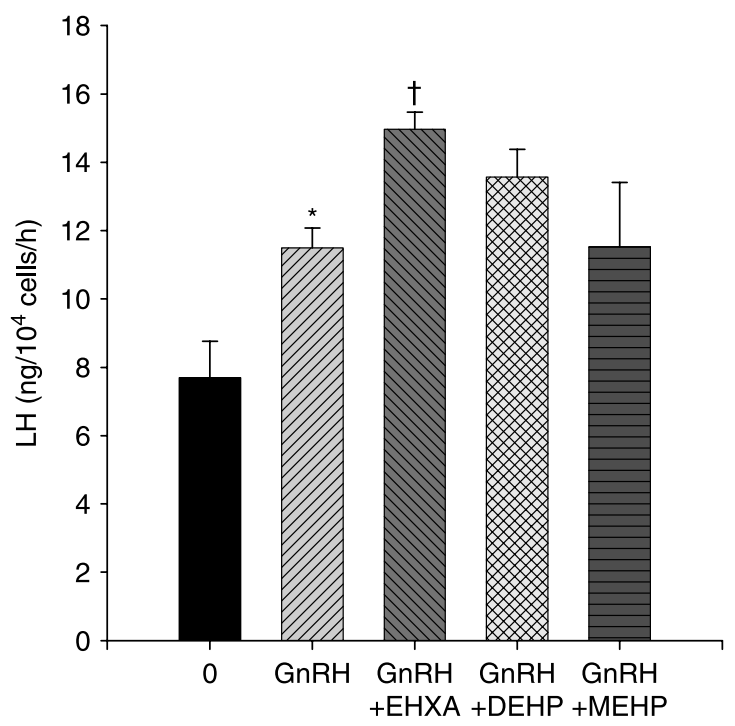

Figure 5 In vitro effects of DEHP and its metabolites, MEHP and 2-ethylhexanoic acid (EHXA), on GnRH-stimulated production of LH by pituitary cells isolated from 20-day-old female rats treated neither with DEHP nor with vehicle. The cells were cultured with or without DEHP, MEHP, or EHXA $(1 \mu \mathrm{M})$ for $24 \mathrm{~h}$ at $37^{\circ} \mathrm{C}$. At this time point, fresh culture medium containing the same compound together with $\mathrm{GnRH}(1 \mathrm{ng} / \mathrm{ml})$ was added and incubation continued for 3 more $h$, after which the concentration of $\mathrm{LH}$ in the culture medium was determined by RIA procedure. These results are means \pm S.E.M. for three independent pituitary cell preparations. ${ }^{*} P<0.05$ when compared with the basal level $(0) ;{ }^{\dagger} P<0 \cdot 05$ when compared with GnRH alone.

\section{Discussion}

The present investigation demonstrates that the treatment of pre-pubertal 20-day-old female rats with DEHP lowers their serum levels of progesterone and estradiol and, at the same time, suppresses progesterone production by and transport of cholesterol into the mitochondria of GCs isolated from their ovaries. In addition, we found that primary cultures of pituitary cells prepared from DEHP-treated rats exhibit an enhanced capacity to secrete $\mathrm{LH}$, which may explain the observed tendency for serum gonadotropin levels to increase in these treated animals. Moreover, we demonstrate here that 2-EHXA, a metabolite of DEHP, significantly enhances GnRH-stimulated production of LH by pituitary cells isolated from 20-day-old female rats that have not been treated in any way. To the best of our knowledge, this is the first example of direct modulation of the hormonal function of the pituitary by a metabolite of DEHP. Together, these results indicate that DEHP exerts a dual effect on the pituitary-ovary axis, both stimulating production of LH by the pituitary and inhibiting steroidogenesis in GCs.

Our observation that administration of DEHP to immature female rats by oral gavage reduces their serum levels of progesterone and estradiol (Fig. 1) is consistent with previous findings that serum levels of cholesterol and triglycerides are lowered by dietary administration of phthalates and/or their metabolites to rats (Moody \& Reddy 1982). Two metabolites of DEHP, 2-ethylhexanol and EHXA, specifically reduce the level of cholesterol, the precursor of all steroid hormones, which may attenuate production of, for example, progesterone and estradiol. This reasoning is also consistent with the previous report that MEHP, one of the major and active metabolites of DEHP, inhibits transcription of the aromatase gene in GCs (Lovekamp \& Davis 2001).

In addition, a decrease in serum levels of estradiol following exposure of cycling rats to DEHP had been observed earlier, along with lowered serum levels of progesterone at certain stages of the estrous cycle (Davis et al. 1994a). Similar inhibition of serum and total ovarian progesterone levels by dibutyl phthalate was shown in female rats during pregnancy (Gray et al. 2006). However, the present study represents for the first time that the ex vivo steroidogenic capacity of GCs isolated from rats receiving DEHP by oral administration has been examined, and we show that the responsiveness of these cells to gonadotropins is attenuated. This may result in decreased production and secretion of progesterone into the serum, which could also contribute to our present findings.

The dose of DEHP $(500 \mathrm{mg} / \mathrm{kg})$ used in this investigation was shown to effectively increase the levels of corticosterone and ACTH in plasma of 20- and 40-day-old male rats (Supornsilchai et al. 2007). As in our study, no overt toxicity was observed in these animals. The dose of DEHP used in this investigation $(500 \mathrm{mg} / \mathrm{kg})$ was lower when compared with doses commonly used by others. In similar studies on female rats, doses of DEHP as high as $1500-2000 \mathrm{mg} / \mathrm{kg}$ have been 
used (Laskey \& Berman 1993, Davis et al. 1994a). In a study on human exposure, the calculated intake of DEHP by women reached a maximum of $15 \mu \mathrm{g} / \mathrm{kg}$ per day (McKee et al. 2004). However, for certain groups of neonatal patients at the neonatal intensive care unit, exposure to DEHP leaching from medical devices could reach $1780 \mu \mathrm{g} / \mathrm{kg}$ per day (Koch et al. 2006). High levels of phthalate metabolites have also been found in human urine (Hauser et al. 2004). These observations show that there is a great deal of uncertainty about the individual levels of exposure to phthalates. Further, to correlate toxic effects observed in animals with acceptable levels of exposure for humans, tenfold increases in the levels of exposure are commonly used to compensate for the inter- and intraspecies variability (Xu et al. 2005).

Transport of cholesterol into the mitochondria of GCs is also impaired by exposure of rats to DEHP. This phenomenon was reflected by the fact that under conditions where further conversion of pregnenolone to progesterone is blocked by trilostane, accumulation of DHEA, the final product, by GC from DEHP-treated rats is significantly less than in the case of control rats. Similar impairment of cholesterol transport in the fetal testis by $\operatorname{di}(n$-butyl $)$ phthalate associated with attenuated expression of scavenger receptor B1 and the steroidogenic acute regulatory protein has been reported (Thompson et al. 2004). The suggestion that inhibition of cholesterol transport is at least one of the deleterious effects of phthalates on steroidogenesis is strongly supported by our finding that in the presence of a cholesterol derivative that readily penetrates membranes, 22R-OHC, GCs from control and DEHP-treated rats produce equal amounts of progesterone.

Our finding that the capacity of pituitary cells isolated from DEHP-treated immature female rats to produce $\mathrm{LH}$ is enhanced might probably reflect less pronounced negative feedback by progesterone and estradiol on the hypothalamus and/or the pituitary of these developing animals. However, our data also indicate that the DEHP metabolite, 2-EHXA, stimulates LH production by the pituitary directly; of course, an indirect action via attenuated negative feedback on the pituitary may also be occurring. The existence of such an indirect action is supported by the observation that exposure of pre-pubertal male rats to DEHP for 28 days stimulated their pituitary-gonadal axis, thereby resulting in elevated serum levels of LH (Akingbemi et al. 2001), as well as by the findings that chronic administration of DEHP to male rats results in hypertrophy of gonadotropes in the anterior pituitary and promotes development of pituitary tumors (Kluwe et al. 1982). Recently, we have also shown that oral exposure of 20 and 40-day-old male rats to DEHP elevates their serum level of ACTH (Supornsilchai et al. 2007).

Although the question as to whether DEHP and/or its metabolites can penetrate the blood-brain barrier remains to be resolved, it seems possible that 2-EHXA, which is a relatively small molecule, can do so. This idea is supported by the fact that the $(R)$-enantiomer of sodium 2-ethylhexanoate is capable of penetrating the placental barrier and exerting severe teratogenic effects in mice (Collins et al. 1992), as well as by our own data revealing that 2-EHXA directly enhances the sensitivity of the gonadotropes to GnRH.

In conclusion, oral administration of DEHP to immature female rats reduces their plasma levels of progesterone and estradiol and enhances the responsiveness of their pituitary cells to GnRH. Such alterations in the HPG axis, caused by exposure to phthalates from various sources, may have deleterious effects on the health of the developing organism.

\section{Acknowledgements}

This work was supported financially by the EU 6th Framework Programme 'Food Quality and Safety', project PIONEER (contract no. 513991), the CASCADE Network of Excellence (EU contract no. FOOD-CT-2004-506319), the Swedish Research Council (project 8282), the Frimurare Barnhuset Foundation in Stockholm, the Swedish Children's Cancer Fund, the Swedish Environmental Protection Agency, HRH Crown Princess Lovisa's Society for Pediatric Health Care, the Society for Child Care, the Wera Ekström Foundation for Pediatric Research, and grants from the Karolinska Institute, Stockholm, Sweden. The authors would like to thank Dr C Carlsson-Skwirut for her help in the iodination of $\mathrm{LH}$ and Josephine Sundborger for her help with the animals. The authors declare that there is no conflict of interest that would prejudice the impartiality of this scientific work.

\section{References}

Akingbemi BT, Youker RT, Sottas CM, Ge R, Katz E, Klinefelter GR, Zirkin BR \& Hardy MP 2001 Modulation of rat Leydig cell steroidogenic function by di(2-ethylhexyl)phthalate. Biology of Reproduction $\mathbf{6 5}$ 1252-1259.

Albro PW, Tondeur I, Marbury D, Jordan S, Schroeder J \& Corbett JT 1983 Polar metabolites of di-(2-ethylhexyl)phthalate in the rat. Biochimica et Biophysic Acta 760 283-292.

Aldyreva MV, Klimova TS, Iziumova AS \& Timofeevskaia LA 1975 The effect of phthalate plasticizers on the generative function. Gigiena Truda $i$ Professional'nye Zabolevaniia 12 25-29.

Brueggemeier RW, Hackett JC \& Diaz-Cruz ES 2005 Aromatase inhibitors in the treatment of breast cancer. Endocrine Reviews 26 331-345.

Collins MD, Scott WJ, Miller SJ, Evans DA \& Nau H 1992 Murine teratology and pharmacokinetics of the enantiomers of sodium 2-ethylhexanoate. Toxicology and Applied Pharmacology 112 257-265.

Davis BJ, Maronpot RR \& Heindel JJ 1994a Di-(2-ethylhexyl) phthalate suppresses estradiol and ovulation in cycling rats. Toxicology and Applied Pharmacology 128 216-223.

Davis BJ, Weaver R, Gaines LJ \& Heindel JJ 1994 b Mono-(2-ethylhexyl) phthalate suppresses estradiol production independent of FSH-cAMP stimulation in rat granulosa cells. Toxicology and Applied Pharmacology 128 224-228

Gray LE, Jr, askey J \& Ostby J 2006 Chronic di-n-butyl phthalate exposure in rats reduces fertility and alters ovarian function during pregnancy in female Long Evans hooded rats. Toxicological Science 93 189-195.

Hauser R, Duty S, Godfrey-Bailey L \& Calafat AM 2004 Medications as a source of human exposure to phthalates. Environmental Health Perspectives $112751-753$. 
Kluwe WM, Haseman JK, Douglas JF \& Huff JE 1982 The carcinogenicity of dietary di(2-ethylhexyl) phthalate (DEHP) in Fischer 344 rats and B6C3F1 mice. Journal of Toxicology and Environmental Health. Part A 10 797-815.

Koch HM, Preuss R \& Angerer J 2006 Di(2-ethylhexyl)phthalate (DEHP): human metabolism and internal exposure- an update and latest results. International Journal of Andrology 29 155-165 (discussion 181-155).

Laskey JW \& Berman E 1993 Steroidogenic assessment using ovary culture in cycling rats: effects of bis(2-diethylhexyl)phthalate on ovarian steroid production. Reproductive Toxicology 7 25-33.

Lovekamp TN \& Davis BJ 2001 Mono-(2-ethylhexyl) phthalate suppresses aromatase transcript levels and estradiol production in cultured rat granulosa cells. Toxicology and Applied Pharmacology 172 217-224.

McKee RH, Butala JH, David RM \& Gans G 2004 NTP center for the evaluation of risks to human reproduction reports on phthalates: addressing the data gaps. Reproductive Toxicology 18 1-22.

Moody DE \& Reddy JK 1982 Serum triglyceride and cholesterol contents in male rats receiving diets containing plasticizers and analogues of the ester 2-ethylhexanol. Toxicology Letters 10 379-383.

Pollack GM, Shen DD \& Dorr MB 1989 Contribution of metabolites to the route- and time-dependent hepatic effects of di-(2-ethylhexyl)phthalate in the rat. Journal of Pharmacological and Experimental Therapeutics 248 176-181.

Potts GO, Creange JE, Hardomg HR \& Schane HP 1978 Trilostane, an orally active inhibitor of steroid biosynthesis. Steroids 32 257-267.
Rowland IR 1974 Metabolism of di-(2-ethylhexyl) phthalate by the contents of the alimentary tract of the rat. Food Cosmetics Toxicology 12 293-303.

Supornsilchai V, Soder O \& Svechnikov K 2007 Stimulation of the pituitaryadrenal axis and of adrenocortical steroidogenesis ex vivo by administration of di-2-ethylhexyl phthalate to prepubertal male rats. Journal of Endocrinology $19233-39$.

Thompson CJ, Ross SM \& Gaido KW 2004 Di(n-butyl) phthalate impairs cholesterol transport and steroidogenesis in the fetal rat testis through a rapid and reversible mechanism. Endocrinology 145 1227-1237.

Treinen KA, Dodson WC \& Heindel JJ 1990 Inhibition of FSH-stimulated cAMP accumulation and progesterone production by mono(2-ethylhexyl) phthalate in rat granulosa cell cultures. Toxicology and Applied Pharmacology 106 334-340.

Xu Y, Cook TJ \& Knipp GT 2005 Effects of di-(2-ethylhexyl)-phthalate (DEHP) and its metabolites on fatty acid homeostasis regulating proteins in rat placental HRP-1 trophoblast cells. Toxicological Science 84 287-300.

Received in final form 21 June 2007

Accepted 26 June 2007

Made available online as an Accepted Preprint 27 June 2007 